\title{
MANAJEMEN ISTANO BASA PAGARUYUNG
}

\author{
Fani Ratny Pasaribu
}

Prodi Magister Administrasi Publik, Fakultas Ilmu Sosial, Universitas Negeri Padang faniratnypasaribu@gmail.com

\begin{abstract}
ABSTRAK
Manajemen pengelolaan Istano Basa Pagaruyung di Batusangkar sangat perlu diperhatikan bagaimana pelaksanaannya, karena apabila manajemen pengelolaan Istano tidak dilakukan dengan baik maka akan menjadi masalah besar untuk Kota Batusangkar. Pokok permasalahan dalam penelitian ini untuk mengetahui manjemen Istano Basa Pagaruyung. Permasalahan itu dapat dilihat dari kendala yang terjadi. Metode penelitian yang digunakan bersifat deskriptif kualitatif dengan dasar penelitian berupa studi kasus. Teknik pengumpulan data dilakukan dalam bentuk studi kepustakaan serta wawancara mendalam. Berdasarkan penelitian diperoleh hasil bahwa Manajemen Istano Basa Pagaruyung di Batusangkar belum berjalan dengan optimal. Karena masih ditemukan hambatan dalam pengelolaannya salah satunya kurangnya perhatian Pemerintah Daerah terhadap kebutuhan Istano mengenai jumlah pegawai dan alokasi anggaran. Sehingga yang terjadi kurangnya penataan di lingkungan Istano. Sebaiknya Pemerintah memberikan perhatian khusus bagi pengembangan objek wisata. Mengingat Istano Pagaruyung merupakan bangunan bernilai budaya tinggi, dan apabila Pemerintah tidak menghiraukannya akan membawa dampak negatif bagi Kota Batusangkar.
\end{abstract}

Kata Kunci: Manajemen, Istano Basa Pagaruyung, Objek Wisata

\begin{abstract}
Management of the Istano Basa Pagaruyung management in Batusangkar is very important to consider in its implementation, because it must be approved that Istano's administrative management is not carried out properly so that it will be a big problem for the City of Batusangkar. The question in this study is to find out the Istano Basa Pagaruyung management. Problems can be seen from the challenges that occur. The research method used is descriptive qualitative research with basic research in the form of case studies. Data collection techniques were carried out in the form of library studies and in-depth interviews. Based on research obtained from the management of Istano Basa Pagaruyung in Batusangkar, it has not run optimally. Because difficulties are still found in management, only a portion of it is of concern to the Regional Government regarding Istano's needs regarding the number of employees and the budget. The importance that occurs in the Istano environment. The government should pay special attention to the development of tourism objects. Taking Istano Pagaruyung is a high cultural value building, and asking the Government to ignore it will have a negative impact on the City of Batusangkar.
\end{abstract}

Keywords: Management, Istano Basa Pagaruyung, Tourism Object 


\section{PENDAHULUAN}

Tanah Datar merupakan salah satu kabupaten yang ada di Sumatera Barat dengan Ibukota Batusangkar. Kabupaten Tanah Datar mempunyai banyak peninggalan sejarah, salah satunya peninggalan sejarah Kerajaan Minangkabau yang berpusat di Pagaruyung yaitu Istano Basa Pagaruyung. Istano ini merupakan icon Sumatera Barat yang sangat terkenal, bahkan sudah menjadi salah satu aset Sumatera Barat. Istano Basa Pagaruyung merupakan bangunan bersejarah yang didirikan oleh raja yang bernama Adityawarman. Istano Basa Pagaruyung merupakan sebutan istana bagi suku Minangkabau. Istano Basa Pagaruyung merupakan objek wisata Primadona Kabupaten Tanah Datar, Istano Basa Pagaruyung dibangun tahun 1976 dan merupakan duplikat Bangunan Rajo Alam Gudam yang dibakar Belanda tahun 1804. Istano Basa Pagaruyung merupakan objek wisata primadona Minangkabau. Dalam pengelolaan objek wisata Istano Basa Pagaruyung di Batusangkar melibatkan beberapa pihak yang terkait, diantaranya Dinas Parpora Kota Batusangkar, UPT Istano Basa Pagaruyung Batusangkar, pihak pengelola Istano Basa Pagaruyung serta melibatkan masyarakat atau komunitaskomunitas yang ada disekitar objek wisata Istano Basa Pagaruyung. Demi berlangsungnya pengelolaan yang baik diperlukan manajemen dalam Istano Basa Pagaruyung. Selain itu pengelolaan yang baik tentunya memerlukan manajemen yang baik dan terarah. Manajemen mencakup kegiatan untuk mencapai tujuan, dilakukan oleh individu- individu yang menyumbangkan upayanya yang terbaik melalui tindakan- tindakan yang telah ditetapkan sebelumnya.
Manajemen pengelolaan Istano Basa Pagaruyung di Batusangkar sangat diperlukan dan sangat diperhatikan bagaimana pelaksanaannya, karena apabila manajemen pengelolaan Istano Basa Pagaruyung tidak dilakukan dengan baik maka akan menambah masalah pada daerah tersebut dan tentunya akan menjadi masalah besar untuk Kota Batusangkar. Salah satu manajemen yang kurang baik yang sangat terlihat dari Istano Basa Pagaruyung adalah kurangnya pegawai di Istano. Kekurangan pegawai ini akan berakibat, terhalangnya pencapaian tujuan secara efektif dan efesien seperti yang direncanakan oleh Dinas Budparpora beserta jajarannya. Potensi yang dimiliki Istano Basa Pagaruyung sangat berpeluang untuk menarik wisatawan baik nusantara maupun mancanegara. Oleh karena itu, perlu adanya pengembangan dengan mengoptimalkan berbagai potensi yang ada dan mengatasi permasalahan yang timbul. Sehubungan dengan hal tersebut kita juga perlu mengetahui apa dampak positif dan dampak yang sangat mendominan dari objek wisata Istano Basa Pagaruyung terhadap Dinas Parpora Batusangkar dan Kota Batusangkar sendiri. Belum optimalnya pengelolaan dan penataan lingkungan dari objek wisata Istano Basa Pagaruyung, perlu mendapat perhatian dari Pemerintah Daerah Tanah Datar selaku pengelola objek wisata. Untuk itu diperlukan pola manajemen pengelolaan diantara unsur-unsur pengelola objek yaitu pemerintah, wisatawan dan masyarakat sekitar. Dan juga diperlukan infrastruktur pendukung, kemampuan untuk mengelola, untuk memberikan kenyamanan, kepuasan bagi wisatawan yang berkunjung, serta dilain pihak dapat memperkecil dampak negatif 
terhadap sumber daya alam, budaya dan masyarakat setempat.

Adapun yang menjadi pokok permasalahan dalam penelitian ini meliputi:

1. Bagaimana proses Manajemen Istano Basa Pagaruyung ?

2. Apa kendala dalam melakukan proses Manajemen Istano Basa Pagaruyung ?

3. Apa upaya yang dilakukan untuk mengatasi kendala tersebut?

\section{KAJIAN PUSTAKA}

\section{Manajemen}

Manajemen berasal dari kata manage (bahasa latinnya: manus) yang berarti: memimpin, menangani, mengatur, atau membimbing. George R. Terry, mendefenisikan manajemen sebagai, "...sebuah proses yang khas dan terdiri dari tindakan- tindakan seperti perencanaan, pengorganisasian, pengaktifan dan pengawasan yang dilakukan untuk menentukan serta mencapai sasaran-sasaran yang telah ditetapkan melalui pemanfaatan sumber daya manusia dan sumbersumber lainnya." Dari defenisi manajemen diatas dapat ditarik suatu kesimpulan bahwa fungsi pokok atau tahapan- tahapan dalam manajemen merupakan suatu proses yang meliputi hal- hal sebagai berikut:

1. Perencanaan (planning) meliputi: penetapan tujuan dan standar, penentuan aturan dan prosedur, pembuatan rencana serta ramalan (prediksi) apa yang akan terjadi.

2. Pengorganisasian (organizing) meliputi: pemberian tugas terpisah kepada masing- masing pihak, membentuk bagian, mendelegasikan dan menetapkan jalur wewenang.

3. Pelaksanaan meliputi usaha agar semua kelompok melaksanakan tujuan dengan kesadaran dan berpedoman pada perencanaan dan usaha pengorganisasian secara efektif.

4. Pengawasan (controlling) didefenisikan sebagai proses penentuan, apa yang harus dicapai yaitu standar, apa yang sedang dilakukan yaitu pelaksanaan, menilai pelaksanaan dan apa perlu melakukan perbaikan- perbaikan, sehingga pelaksanaan sesuai dengan standar dan selaras dengan yang diinginkan.

\section{Tujuan Manajemen}

1. Menjalankan dan mengevaluasi strategi yang telah direncanakan agar dapat berjalan secara efektif.

2. Melakukan peninjauan kembali terhadap implementasi fungsi manajemen serta kinerja para anggota dalam melaksanakan tugasnya.

3. Memperbaharui strategi pelaksanaan fungsi manajemen agar tetap dapat mencapai target.

4. Melakukan peninjauan kembali terhadap kekuatan, kelemahan, serta ancaman pada organisasi.

5. Merancang inovasi yang dapat meningkatkan efektivitas kinerja para anggota.

\section{Manajemen Publik}

Manajemen publik atau dapat juga disebut manajemen pemerintah secara umum merupakan suatu upaya pemerintah dalam pemenuhan kebutuhan publik dengan menggunakan sarana dan prasarana yang tersedia. Unsur manajemen saat ini menjadi suatu unsur penting dalam penyelenggaraan organisasi, baik organisasi pada sektor swasta maupun dalam sektor publik seperti organisasi 
pemerintahan. Konsep Manajemen Publik terbagi atas:

1. Old Public Administration

2. New Public Management

3. New Public Service

\section{Istano Basa Pagaruyung}

Raja Adityawarman dilahirkan pada tahun 1295 Masehi di Majapahit. Dia dibesarkan dan dididik di Majapahit dan pernah menjabat jabatan tinggi di Majapahit sebagai senopati utama (panglima utama dari tentara Majapahit). Kerajaan Pagaruyung didirikan oleh Raja Adityawarman pada tahun 1343, yang awalnya meliputi wilayah bekas kerajaan Bunga Setangkai dan wilayah bekas Kerajaan Dharmasraya. Sebelum kerajaan Pagaruyung di Minangkabau, sudah ada Kerajaan- kerajaan lainnya secara silih berganti antara lain:

1. Kerajaan Pasumayan Koto Baru, yang berpusat di Pariangan, dikaki gunung merapi berusia kurang lebih 3 abad sebelum masehi.

2. Kerajaan Lagundi Baselo yang berpusat di Pariangan Padang Panjang, berusia dari pertengahan abad ke-2 Masehi sampai pertengahan abad ke-5 Masehi.

3. Kerajaan Bunga Setangkai yang berpusat di Sungai Tarab, yang usianya dari pertengahan abad ke-5 Masehi sampai pertengahan abad ke-14 Masehi.

\section{Sistem Pemerintahan Kerajaan Pagaruyung}

Situasi pemerintahan di Kerajaan Pagaruyung ketika diperintah oleh Adityawarman, menerapkan sistem autokrasi dan demokrasi. Adityawarman meninggalkan sistem demokrasi yang telah berlaku di
Minangkabau. Sistem lama yang merupakan pemerintahan federasi, berpematang bagi sawah, berbintalak bagi kebun, mulai ditinggalkan oleh Adityawarman. Dalam menjalankan pemerintahan, Adityawarman dibantu oleh Datuk Ketemanggungan. Masuknya pengaruh Islam ke Kerajaan Pagaruyung, secara langsung berimplikasi terhadap sistem pemerintahan. Sistem pemerintahan di Kerajaan Pagaruyung mengalami perubahan yang berdasarkan adat dan syarak, "Adat Basandi Syarak dan Syarak Basandi Kitabullah."

\section{METODE PENELITIAN}

Metode yang digunakan dalam penelitian ini adalah metode penelitian kualitatif. Penelitian kualitatif bertujuan untuk mengungkapkan informasi kualitatif sehingga lebih menekankan pada masalah proses dan makna dengan mendeskripsikan suatu masalah. Penelitian yang dilakukan bersifat deskriptif, yaitu untuk mengetahui atau menggambarkan kenyataan dari kejadian yang diteliti atau penelitian yang dilakukan terhadap variabel mandiri atau tunggal, yaitu tanpa membuat perbandingan atau menghubungkan dengan variabel lain.

Menurut Sugiono, populasi adalah wilayah generalisasi yang terdiri atas objek/subjek yang mempunyai kualitas dan karateristik tertentu, yang ditetapkan oleh peneliti untuk dipelajari dan kemudian ditarik kesimpulan. Sesuai dengan pemahaman tersebut maka populasi dalam penelitian ini adalah seluruh pegawai Istano Basa Pagaruyung yang bekerja di Istano Basa Pagaruyung Batusangkar.

Sampel adalah bagian dari populasi yang memiliki sifat-sifat yang sama dari objek yang merupakan sumber data. Jadi jumlah sampel dalam penelitian ini adalah : 
1. Kepala Dinas Parpora Kota Batusangkar satu (1) orang.

2. Kepala UPT Istano Basa Pagaruyung Batusangkar satu (1) orang.

3. Pengelola Istano basa Pagaruyung Batusangkar empat (4) orang.

4. Masyarakat disekitar Istano Basa Pagaruyung tiga (3) orang.

5. Pengunjung wisata Istano Basa Pagaruyung lima (5) orang.

\section{HASIL PENELITIAN PEMBAHASAN}

\section{Manajemen Istano Basa Pagaruyung}

Penulis mendapatkan informasi mengenai bagaimana manajemen Istano Basa Pagaruyung melalui wawancara dengan informan yang merupakan bagian dari BUDPARPORA (Dinas Kebudayaan Pariwisata Pemuda dan Olahraga Kabupaten Tanah Datar) yaitu Kepala UPT Istano Basa Pagaruyung yang ditugaskan untuk mengelola Objek Wisata Istano Basa Pagaruyung. Tentunya dalam hal ini penulis juga melakukan wawancara dengan pegawai-pegawai yang telah profesional atau yang telah berpengalaman.

Menurut penjelasan dari bapak Kepala UPT Istano Basa Pagaruyung (2017), Istano Basa Pagaruyung merupakan lambang adat minangkabau yang terletak di Kabupaten Tanah Datar, Nagari Pagaruyung. Secara keseluruhan manajemen Istano Basa Pagaruyung dikelola oleh Pemerintah Daerah (PEMDA) dibawah naungan Dinas Pariwisata Pemuda dan Olahraga (Parpora) dan dikelola secara langsung oleh Kepala UPT Pagaruyung, Sekretaris UPT Pagaruyung dan sederet jajaran UPT Pagaruyung. Dengan rincian nya: Pegawai Negri Sipil (PNS) (4 orang), Cleaning Service (19 orang), Satpam (7 orang), Tiketting (4 orang),
Gaide (3 orang), IT (1 orang). Total pegawai yang bekerja di Istano Basa Pagaruyung sekarang ini adalah sebanyak 38 orang. Dengan jumlah itu mereka melaksanakan tugas masingmasing sesuai dengan Tugas pokok dan fungsi (Tupoksi) yang berlaku.

Melakukan pengelolaan objek wisata Istano Basa Pagaruyung di Kabupaten Tanah Datar oleh Dinas Budaya Pariwisata Pemuda dan Olahraga dibutuhkan perencanaan yang tepat dan matang, diantaranya:

\section{Perencanaan}

Perencanaan sebagai dasar untuk pencapaian tujuan dan standar yang telah ditetapkan dalam manajemen Istano Basa Pagaruyung sebagai tujuan objek wisata di Batusangkar. Perencanaan digunakan untuk menentukan tujuan organisasi secara keseluruhan dan yang terbaik untuk memenuhi tujuan tersebut melalui penetapan atau penentuan organisasi, sistem, anggaran, dan standar yang dibutuhkan untuk mencapai tujuan. Merencanakan berarti mempersiapkan segala kebutuhan, memperhitungkan matang- matang apa saja yang menjadi kendala, dan merumuskan bentuk pelaksanaan kegiatan. Salah satu kegiatan pariwisata yang dilakukan oleh Pemerintah Kabupaten Tanah Datar adalah mengelola objek wisata Istano Basa Pagaruyung, yang tujuannya adalah menjadikan objek wisata Istano basa Pagaruyung ini sebagai icon pariwisata Kabupaten Tanah Datar Maupun Provinsi Sumatra Barat suapaya dikenal oleh masyarakat luas.

2. Pengorganisasian

Sesuai dengan teori yang dikatakan oleh George R. Tery tersebut, penerapan dilapangan yang dilihat oleh peneliti sebagai berikut:

a) Pemberian tugas terpisah kepada masing- masing pihak. 
Kepala UPT Istano Basa Pagaruyung telah menetapkan aturan sesuai dengan Tupoksinya kepada setiap pegawai hal tersebut sesuai dengan UU yang dibuat oleh Kepala UPT Istano Basa Pagaruyung. Contoh yang terlihat adalah satpam sangat tegas dalam mengatur pengunjung yang melanggar aturan dan gaide memberikan pelayanan yang puas kepada pengunjung.

b) Membentuk bagian.

Setiap pegawai Istano Basa Pagaruyung membentuk bagian atau kelompok dalam bertugas sesuai dengan jalurnya masing- masing. Tujuannnya adalah agar pelayanan yang diberikan kepada pengunjung tidak lagi terasa canngung.

c) Mendelegasikan dan menetapkan jalur wewenang

Pemerintah Kabupaten Tanah Datar Dinas Budaya Pariwisata Pemuda dan Olahraga telah menetapkan jalur wewenang kepada Unit Pelaksana Teknis (UPT) Pagaruyung, agar Pegawai- Pegawai istano Basa Pagaruyung beserta Staf lainnya dapat menjalankan tugas dan kewajibannya dengan baik dan benar. Agar tujuan yang telah ditetapkan sebelumnya dapat tercapai dengan baik pula.

d) Menetapkan sistem komunikasi.

Kepala UPT Istano Basa Pagaruyung telah menetapkan aturan kepada setiap pegawai Istano Basa Pagaruyung harus menetapkan komunikasi yang baik dan ramah kepada setiap pengunjung yang datang. Terlebih kepada setiap gaide yang akan memandu pengunjung yang datang dari domestik ataupun mancanegara.

e) Kepala UPT Istano Basa Pagaruyung bertugas untuk mengkoordinir kerja setiap karyawan sesuai dengan kemampuan dan keahliannya dalam perencanaan yang sudah direncanakan.

3. Pelaksanaan

Pelaksanaan yang dimaksudkan disini adalah bagaimana Pemerintah Kabupaten Tanah Datar dapat melaksanakan perencanaanperencanaan yang telah dibuat sebelumnya. Serta Kepala Unit Pelaksana Teknis dapat mengkoordinir setiap pegawai Istano basa Pagaruyung agar melakukan pekerjaan masingmasing dengan baik dan tepat sasaran. Dan yang paling penting juga adalah setiap pegawai Istano Basa Pagaruyung dapat bekerja secara Individual, Team maupun secara kelompok. Tugas pokok masing- masing individu yang sudah dibuat sebelumnya pun agar dapat dikerjakan oleh setiap pegawai Istano Basa Pagaruyung dengan sebaikbaiknya agar tujuan yang ditetapkan sebelumnya dapat tercapai dengan baik.

4. Pengawasan

Tahap pengawasan terhadap pelaksanaan dari perencanaan pengelolaan objek Wisata Istano Basa Pagaruyung yang dilakukan oleh Dinas Pariwisata Pemuda dan Olahraga, Inspektorat Kabupaten Tanah Datar dan Badan Pemeriksa Keuangan Provinsi Sumatra Barat, harus dilakukan dengan sebaik- baik mungkin agar tidak terjadi kekeliruan dalam pengurusan segala urusan yang ada di dalamnya. Jika hal tersebut sudah berjalan dengan baik, maka pengawasan objek wisata Istano Basa Pagaruyung akan berjalan dengan baik sesuai dengan tujuan yang telah ditentukan sebelumnya. Apabila dalam tahap pelaksanaan terjadi hal- hal yang tidak diinginkan maka perlu dilakukan perbaikan- perbaikan guna kelancaran tahap pengawasan yang ada di Istano Basa Pagaruyung. 
Manajemen pengelolaan Objek Wisata Istano Basa Pagaruyung yang kurang baik, dapat mempengaruhi pendapatan asli daerah. Untuk itu perlu upaya untuk mengoptimalkan kegiatan kepariwisataan di Istano Basa Pagaruyung agar wisatawan baik local maupun mancanegara bisa lebih lama mendapatkan pengalaman yang berbeda. Untuk itu sangat diperlukan manajemen pariwisata diantara unsurunsur pengelola objek wisata yaitu pemerintah, wisatawan, dan masyarakat sekitarnya.

\section{Kendala Manajemen Istano Basa Pagaruyung}

Berdasarkan wawancara dengan informan pada tahun 2017, kendalakendala yang dihadapi oleh petugas dalam melaksanakan tugasnya, adalah sebagai berikut:

1. Sarana dan prasarana transportasi untuk menjangkau objek wisata Istano Basa Pagaruyung masih mengalami kesulitan, karena sebagian besar masih menggunakan kendaraan pribadi. Sulitnya transportasi menuju Istano Basa Pagaruyung membuat masyarakat kesusahan untuk mengunjungi Istano Basa Pagaruyung pada hari- hari biasa. Ini bisa saja membuat Istano Basa Pagaruyung menjadi sepi pengunjung. Dan akan sangat ramai ketika hari- hari Libur Nasional.

2. Sarana dan prasarana penunjang atraksi wisata masih terbatas. Sarana penunjang yang dimaksud adalah masih kurangnya pakaian adat di Istano Basa Pagaruyung yang dapat dipakai oleh masyarakat yang datang berkunjung. Sehingga masyarakat harus mengantri terlebih dahulu sebelum memakai pakaian adat tersebut.

3. Kurangnya peran serta masyarakat dalam mengembangkan objek wisata. Jika masyarakat setempat atau masyarakat Kota Batusangkar lebih mengeksplor peninggalan sejarah Istano Basa Pagaruyung, tentunya akan membawa dampak yang baik bagi daerah itu sendiri. Akan tetapi hal tersebut masih sangat minim dilakukan oleh masyarakat Kota Batusangkar.

\section{Upaya Mengatasi Kendala Manajemen Istano Basa Pagaruyung}

Upaya-upaya yang dilakukan dalam mengatasi kendala dalam Manajemen Istano Basa Pagaruyung berdasarkan wawancara dengan beberapa informan pada tahun 2017, sebagai berikut:

1. Peningkatan Sarana dan Prasarana.

Wawancara yang peneliti lakukan dengan Bapak Maiyandri, kepala Staff Fungsional Istano Basa pagaruyung mengatakan sarana dan prasarana pada dasarnya memiliki fungsi utama sebagai berikut: mempercepat proses pelaksanaan pekerjaan sehingga dapat menghemat waktu, meningkatkan produktivitas, baik barang dan jasa, hasil kerja lebih berkualitas dan terjamin, lebih memudahkan/sederhana dalam gerak para pengguna/pelaku, ketepatan susunan stabilitas pekerja lebih terjamin, menimbulkan rasa kenyamanan bagi orang-orang yang berkepentingan, menimbulkan rasa puas pada orang-orang yang berkepentingan yang mempergunakannya.

Pemerintah berupaya melakukan perencanaan mengenai gambaran terhadap objek wisata yaitu program pembangunan fisik atau sarana dan 
prasarana pokok wisata, kemudian pemerintah juga membuat perencanaan mengenai sarana dan prasarana pelengkap/ penunjang dengan cara bekerja sama dengan masyarakat.

\section{Penyediaan Anggaran}

Agar manajemen dalam Istano Basa Pagaruyung dapat berjalan sesuai dengan tujuan yang diharapkan maka perlu penyediaan anggaran dari Dinas Parpora Batusangkar. Serta tentunya adanya anggaran pemerintah pusat melalui Dana Alokasi Khusus dalam pengembangan Istano Basa Pagaruyung kedepannya.

\section{Sumber Daya Manusia yang} Terampil dan Profesional

Pengembangan pariwisata akan berhasil apabila salah satu faktor pentingnya tercapai. Yaitu adanya sumber daya manusia yang berkualitas, terampil dan profesional. Contoh yang sangat penting adalah pelayanan kepada masyarakat baik domestik maupun mancanegara yang berkunjung ke Istano Basa Pagaruyung. Pegawai Istano tidak lagi menganggap pengunjung sebagai Raja. Melainkan pengunjung atau tamu adalah mitra. Pegawai Istano dan pengunjung juga saling take and give, sehingga pelayanan pun terasa tidak canggung.Pegawai Istano tetap memberikan pelayanan yang prima kepada pengunjung dan tetap menegur pengunjung yang melakukan perbuatan salah dengan baik.

\section{PENUTUP}

Manajemen pengelolaan objek wisata Istano Basa Pagaruyung yang kurang baik, dapat mempengaruhi pendapatan asli daerah. Untuk itu perlu upaya untuk mengoptimalkan kegiatan kepariwisataan di Istano Basa Pagaruyung agar wisatawan baik local maupun mancanegara bisa lebih lama mendapatkan pengalaman yang berbeda di lokasi objek wisata. Untuk itu dibutuhkan perencanaan, pengorganisasian, pelaksanaan dan pengawasan yang tepat dan matang dalam manajemen Istano Basa Pagaruyung Batusangkar. Belum optimalnya pengelolaan dan penataan lingkungan dari objek wisata budaya Istano Basa Pagaruyung sangat perlu mendapat perhatian dari Pemerintah Daerah Tanah Datar selaku pengelola objek wisata. Karena jika Pemerintah tidak menghiraukan objek wisata Istano Basa Pagaruyung, akan membawa dampak negatif atau efek yang tidak baik bagi Kota Batusangkar.

Sebaiknya Pemerintah Daerah Tanah Datar Batusangkar memberikan perhatian khusus bagi pengembangan objek wisata Istano Basa Pagaruyung. Mengingat Istano Basa Pagaruyung merupakan bangunan bernilai budaya tinggi yang mencerminkan budaya masyarakat minangkabau. Hendaknya Pemerintah Daerah memberikan anggaran yang dibutuhkan untuk pengembangan pariwisata agar lebih maju, kemudian mengusulkan dana ke tingkat provinsi dan pusat untuk mengembangkan objek wisata yang ada. Dan setelah dana yang diinta sudah diturunkan, supaya dana itu digunakan sebaik- baiknya hanya untuk kepentingan pengembangan Objek wisata Istano Basa Pagaruyung.

\section{REFERENSI}

Bappeda dan PM Kab. Tanah Datar Batusangkar. (2012). Profil Daerah Kabupaten Tanah Datar Tahun 2012. Batusangkar.

Maleong Lexi J., (2001). Metode Penelitian Kualitatf. Bandung: Remaja Rosdakarya. 
Martamin et.al Mardjamni. (2002). Sejarah Perjuangan Minangkabau, Sumatra Barat: Masyarakat Sejarawan Indonesia (MSI) bekerjasama dengan Dinas Pariwisata Seni dan Budaya Sumatera Barat.

Marzuki. (1997). Metode Riser. BPFE: Yogyakarta.

Nabawi Hadari. (1992). Instrumen Penelitian Bidang Sosial. Yogyakarta: Gadjah Mada University Pres.

Sugiono. (2001). Metode Penelitian Administrasi. Bandung: PT.Alfabeta.

Terry George R.. (1986). Asas- Asas Manajemen. Bandung: P.T. Alumni.

Terry, George R. (2014). Prinsipprinsip Manajemen. Jakarta: PT. Bumi aksara.

Toeah, Datoek. (1976). Tambo Alam Minangkabau. Bukittinggi: Pustaka Indonesia.

Wilson, wodrow. (2008). Konsep Manajemen Publik. Jakarta: PT. Bumi Aksara.

Wawancara dengan Bapak Ridwan. Kepala UPT Istano Basa Pagaruyung. Pada tanggal 9 Desember 2017.

Wawancara dengan Bapak Maiyandri. Staf FungsionalUmum UPT Istano Basa Pagaruyung. Pada tanggal 10 Desember 2017.

https://www.kembar.pro/2015/05/peng ertian-dan-peranan-utamamanajemen.html?m=1 diakses pada tanggal 11 November 2017 pukul 14.00 Wib.

http://www.fungsiklopedia.com/fungsimanajemen/ diakses pada tanggal 11 November 2017 pukul 15.00 Wib

http://erepo.unud.ac.id/16248/2/089037 1003-2-BAB_I.pdf diakses pada tanggal 28 Oktober 2017 pukul $15.40 \mathrm{Wib}$

repository.unand.ac.id/21434/3/bab\%2 01.pdf repository.unand.ac.id/20463/1/Jurnal \%20Pratiwi\%20Rahmadani.pdf 